\title{
Proximity to coke works and hospital admissions for respiratory and cardiovascular disease in England and Wales
}

\author{
P Aylin, A Bottle, J Wakefield, L Jarup, P Elliott
}

\begin{abstract}
Background-The incidence of hospital admissions for respiratory and cardiovascular diseases in areas close to operating coke works in England and Wales was investigated.

Methods-A small area study using distance from source as a proxy for exposure was undertaken in subjects aged 65 or over and children under 5 years within $7.5 \mathrm{~km}$ of four coke works (1991 estimated populations 87760 and 43 932, respectively). The main outcome measures were emergency hospital admissions in 1992/3-1994/5 with a primary diagnosis of coronary heart disease (ICD 410-414), stroke (ICD 431-438), all respiratory diseases (ICD 460-519), chronic obstructive pulmonary disease (ICD 491-492), and asthma (ICD 493 ) in those aged 65 or over, and all respiratory and asthma admissions in children under 5 years of age.
\end{abstract}

Results-At age 65 or over the combined estimate of relative risk with proximity to coke works (per $\mathbf{k m}$ ) ranged from 0.99 (95\% CI 0.90 to 1.09 ) for chronic obstructive pulmonary disease to $1.03(95 \% \mathrm{CI}$ 0.94 to 1.13) for asthma. For children under 5 years the combined estimate of risk was 1.08 (95\% CI 0.98 to 1.20$)$ for all respiratory disease and 1.07 (95\% CI 0.98 to 1.18) for asthma. There was evidence of significant heterogeneity in risk estimates between coke work groups, especially in children under 5 years $(p<0.001$ and $\mathrm{p}=0.004$ for respiratory disease and asthma, respectively). For the Teesside coke works in North East England the relative risk with proximity (per $\mathrm{km}$ ) was $1.09(95 \%$ CI 1.06 to 1.12$)$ for respiratory disease and 1.09 (95\% CI 1.04 to 1.15$)$ for asthma.

Conclusions-No evidence overall was found for an association between hospital admissions and living near operational coke works in England and Wales. Trends of a higher risk of hospital admission for respiratory disease and asthma among children with proximity to the Teesside plant require further investigation.

(Thorax 2001;56:228-233)

Keywords: epidemiology; respiratory disease; air pollution

Acute rises in the levels of air pollution are associated with acute ill health and excess mortality, ${ }^{1-3}$ especially from cardiorespiratory diseases. Recent attention has focused on particulate pollution, ${ }^{45}$ although other pollutants including sulphur dioxide ${ }^{6}$ and ozone ${ }^{7}$ are also implicated. Much less is known about the effects of chronic exposure to air pollution on health, ${ }^{8-10}$ including possible effects in people living close to industrial sources. ${ }^{11-13}$ Coke works are an important local source of particulate and sulphurous pollution and complex mixtures of pollutants. ${ }^{14}$ Sulphur dioxide, oxides of nitrogen, and particulates (as black smoke and soot) are continually released from the main stack. The majority of particulates are released on an intermittent basis (typical frequency of the order of half hourly) during discharge and quenching of coke. Other organic pollutants such as benzene and polyaromatic hydrocarbons are released from fugitive sources. ${ }^{15}$

Three recent studies have examined the health of residents near coke works in the UK. Bhopal $\mathrm{et}_{\mathrm{al}} \mathrm{l}^{16}$ found increased rates of symptom reporting for respiratory and ear, nose and throat complaints among residents (especially children) living near Monkton coke works, and increased all cause mortality among children, but not adults. Dolk et $a l^{17}$ found a small excess in mortality within $2 \mathrm{~km}$ of coke works and a decline in mortality with distance from coke works, but could not exclude residual socioeconomic confounding as an explanation. The third study found no evidence of an increased risk of perinatal and infant mortality and low birth weight among infants born to mothers living near coke works. ${ }^{18}$

This study investigates the incidence of hospital admissions for respiratory and cardiovascular diseases in areas close to operating coke works in England and Wales. There is evidence to suggest that hospital use is a reasonable proxy for morbidity for some conditions such as respiratory disease. ${ }^{19}$ The focus is on potentially vulnerable groups-people aged 65 or over who may have limited respiratory reserve, and children under 5 years. ${ }^{20}$

\section{Methods}

Nine coke works still operational in England and Wales in 1995 were eligible for study (there were none in Scotland). They fell into six groups of sites, based on proximity between adjacent coke works (table 1, fig 1). Hospital Episode Statistics and the Patient Episode Database for Wales for the years 1992/3 to 1994/5, held by the UK Small Area Health Statistics Unit, provided numbers of emer- 
Table 1 Operating coke works in England and Wales in 1995, and 1991 population estimates within $7.5 \mathrm{~km}$ at ages $\geqslant 65$ and $0-4$ years

\begin{tabular}{lllr}
\hline Area & Operating coke works & \multicolumn{2}{l}{1991 population } \\
\cline { 3 - 3 } & & $\geqslant 65$ years & 0-4 years \\
\hline England & & \\
$\quad$ Royston & Monkton coking works & 23976 & 11362 \\
Scunthorpe & Appleby coke ovens & 13985 & 6569 \\
$\quad$ Teesside & South Bank coke ovens & 31541 & 17107 \\
Wales & & & \\
Newport & Llanwern works & 18258 & 8894 \\
Pontypridd ${ }^{\star}$ & Cwm coking works & 14965 & 7795 \\
Port Talbot & Morfa coking works & 9638 & 3598 \\
& Grange coking plant & & \\
\hline
\end{tabular}

${ }^{\star}$ Excluded from the study because of incomplete data on hospital admissions (see text).

gency hospital admissions (irrespective of whether they came via A\&E or GP referral) among people whose census enumeration districts of residence had population weighted centroids within $7.5 \mathrm{~km}$ of the nearest coke works. Since an admission may comprise several episodes as patients are transferred from one consultant to another within the same trust, the first episode was used to identify an admission. Patients may be included more than once if they are discharged and later readmitted either to the same or to a different trust. Population estimates for 1991 (by 5 year age group, sex, and quintile of the Carstairs deprivation score $^{21}$ ) were obtained for each enumeration district (ED) using figures from the "estimating with confidence" project. ${ }^{22}$ Enumeration districts contain, on average, about 400 people. Diseases examined at age 65 years or over were coronary heart disease (ICD 410-414), stroke (ICD 431-438), all respiratory diseases (ICD 460-519), chronic obstructive pulmonary disease (ICD 491-492), and asthma (ICD 493). All respiratory diseases and asthma were examined in children under 5 years. The primary diagnosis was used in all cases.

Two hospitals serving residents near Pontypridd and Port Talbot coke works failed to record a primary diagnosis or used the ICD 9th revision code 799 (other ill defined and unknown causes of morbidity and mortality) in $25 \%$ and $36 \%$ of their emergency admissions, respectively, ${ }^{23}$ while figures for the remaining

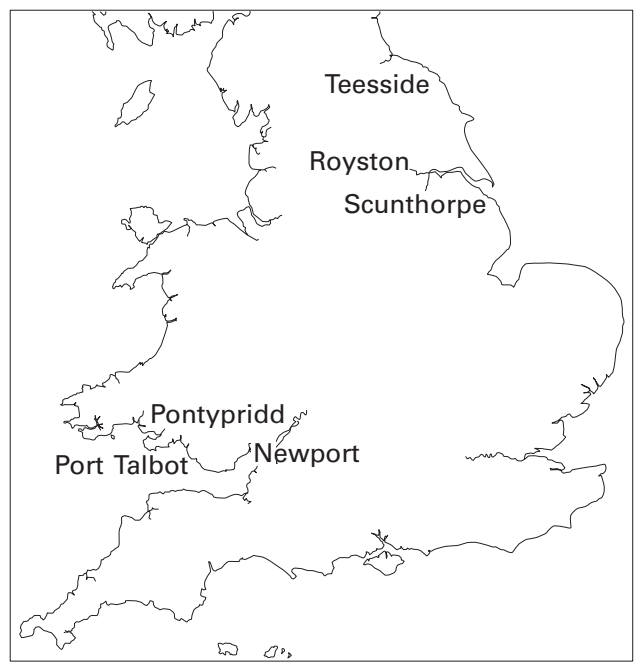

Figure 1 Location of six groups of operating coke works operational in England and Wales in 1995. hospitals varied between $1 \%$ and $11 \%$. These two groups (three coke works) were therefore excluded, leaving six coke works in four groups for study (table 1). Fewer than 1\% of cases within $7.5 \mathrm{~km}$ of coke works in England were omitted because of missing data for method of admission, age, sex, postcode, and primary diagnosis. For Newport, 3.3\% had missing or invalid fields.

Ideally the exposure model would be based on direct measurement or modelling using, for example, stack height, operating conditions, wind direction, and other meteorological factors, but these data were not available for all of the sites. In the absence of such modelling we used a distance-decline model based on concentric areas around the coke works. ${ }^{24}$ Using the relevant administrative region as the reference population, expected numbers of admissions, by specific cause, were calculated for each enumeration district within $7.5 \mathrm{~km}$ of a coke works. An indirectly standardised admission ratio (relative risk (RR) estimate) by age, sex, and Carstairs quintile was calculated from the ratio of observed to expected numbers of cases around each coke work group based on location of the population centroids of the underlying EDs for seven distance bands around each group with outer radii of $1,2,3$, $4.6,5.7,6.7$, and $7.5 \mathrm{~km}$. Stone's conditional test $\mathrm{t}^{25}$ for decline in risk with distance was performed, with significance levels based on 999 simulations.

The specification of the form of the relation between risk of admission and distance from coke works is of particular importance. Several choices are available including linear, step, or inverse square and these were explored using the method of Diggle et $a .^{26}$ In view of problems such as model convergence with the more complicated forms, the linear model was preferred and Poisson regression, with distance included as a continuous variable, was used to provide an estimate of the risk of admission associated with proximity to coke works.

To adjust for possible "provider effects"that is, the variation between hospitals in admission rates due to factors such as differences in hospital admissions policy and clinical coding - "hospital" was included as an additional categorical covariate in the Poisson regression analyses. Whereas the number of cases going to each hospital is known, the population who are "at risk" of admission to each hospital is not and must be estimated. To this end, the fraction of each ward's total emergency admissions going to each local hospital (including an artificial "other" provider, created to capture remaining admissions) was calculated. Populations in each ED within the ward were then multiplied by this set of fractions and the regression proceeded as before. This tended to improve the fit of the model and reduce overdispersion.

Estimates of association with proximity to each coke works were then combined in a Bayesian hierarchical (random effects) model using the BUGS software ${ }^{27}$ in order to find an overall estimate of association. 
Table 2 Numbers and rates of emergency hospital admissions in 1992/3-1994/5 within $7.5 \mathrm{~km}$ at ages $\geqslant 65$ and 0-4 years

\begin{tabular}{|c|c|c|c|c|c|c|c|c|}
\hline \multirow[b]{3}{*}{ Area } & \multicolumn{4}{|c|}{ Age $\geqslant 65$ years } & \multicolumn{4}{|c|}{ Age 0-4 years } \\
\hline & \multicolumn{2}{|c|}{ Respiratory disease } & \multicolumn{2}{|c|}{ CHD/stroke } & \multicolumn{2}{|c|}{ Respiratory disease } & \multicolumn{2}{|c|}{ Asthma } \\
\hline & No & $\begin{array}{l}\text { Crude rate per } \\
\text { 1000/year }\end{array}$ & No & $\begin{array}{l}\text { Crude rate per } \\
\text { 1000/year }\end{array}$ & No & $\begin{array}{l}\text { Crude rate per } \\
\text { 1000/year }\end{array}$ & No & $\begin{array}{l}\text { Crude rate per } \\
\text { 1000/year }\end{array}$ \\
\hline Royston & 2555 & 36 & 2717 & 38 & 1549 & 45 & 374 & 11 \\
\hline Scunthorpe & 1295 & 31 & 1984 & 47 & 1066 & 54 & 229 & 12 \\
\hline Teesside & 2664 & 28 & 3178 & 34 & 3048 & 59 & 804 & 16 \\
\hline Newport & 848 & 15 & 1275 & 23 & 845 & 32 & 252 & 9 \\
\hline
\end{tabular}

$\mathrm{CHD}=$ coronary heart disease .

\section{Results}

In 1991 an estimated 87760 people aged 65 or over and 43932 children under 5 years of age lived within $7.5 \mathrm{~km}$ of the four coke work groups included in the study (table 1).

Table 2 shows numbers of admissions and crude rates per 1000 population per year at ages 65 or over, and for children under 5 years. At the age of 65 or over there were a total of 7362 emergency admissions for respiratory disease within $7.5 \mathrm{~km}$ with crude rates ranging from 15 to 36 per 1000 population per year and 9154 admissions for coronary heart disease and stroke with rates ranging from 23 to 47 per 1000 population per year. In children under 5 years of age there were 6508 respiratory disease admissions within $7.5 \mathrm{~km}$ with crude rates ranging from 32 to 59 per 1000 population per year and 1659 admissions for asthma with rates ranging from 9 to 16 per 1000 population per year.

For people aged 65 or over no consistent patterns emerged (fig 2). With deprivation and provider adjustment there was a significantly lower risk with proximity (per $\mathrm{km}$ ) to Royston for all respiratory disease (RR 0.95, 95\% CI 0.93 to 0.98 ), a borderline significantly lower risk near Royston for stroke (RR 0.96, 95\% CI 0.93 to 1.00 ) and Newport for coronary heart disease (RR 0.94, 95\% CI 0.89 to 1.00 ), and a borderline significantly higher risk for coronary heart disease near Teesside (RR 1.04, 95\% CI 1.00 to 1.08$)$. None of the other regression estimates was significant and none of the overall estimates for coke works combined showed a significant association in either direction (fig 2).

Results for children under 5 years are given in fig 2 and presented in table 3 . The table shows RR estimates for seven distance bands around the coke works, as well as the results of Stone's conditional test and the Poisson regression analyses. Overall the Bayesian random effects model, including adjustment for deprivation and provider, indicated a combined RR estimate (per km proximity) of 1.08 (95\% CI 0.98 to 1.20 ) for all respiratory disease and 1.07 (95\% CI 0.98 to 1.18 ) for asthma. Using the method of moments, ${ }^{28}$ there was evidence of significant heterogeneity between the regression estimates for the four coke work groups $(p<0.001$ for respiratory disease and $\mathrm{p}=0.004$ for asthma with provider adjustment).

For the Teesside coke works the Stone's test indicated a significantly higher risk with proximity to the coke works for all respiratory disease $(p=0.001)$ and for asthma $(p=0.024)$,

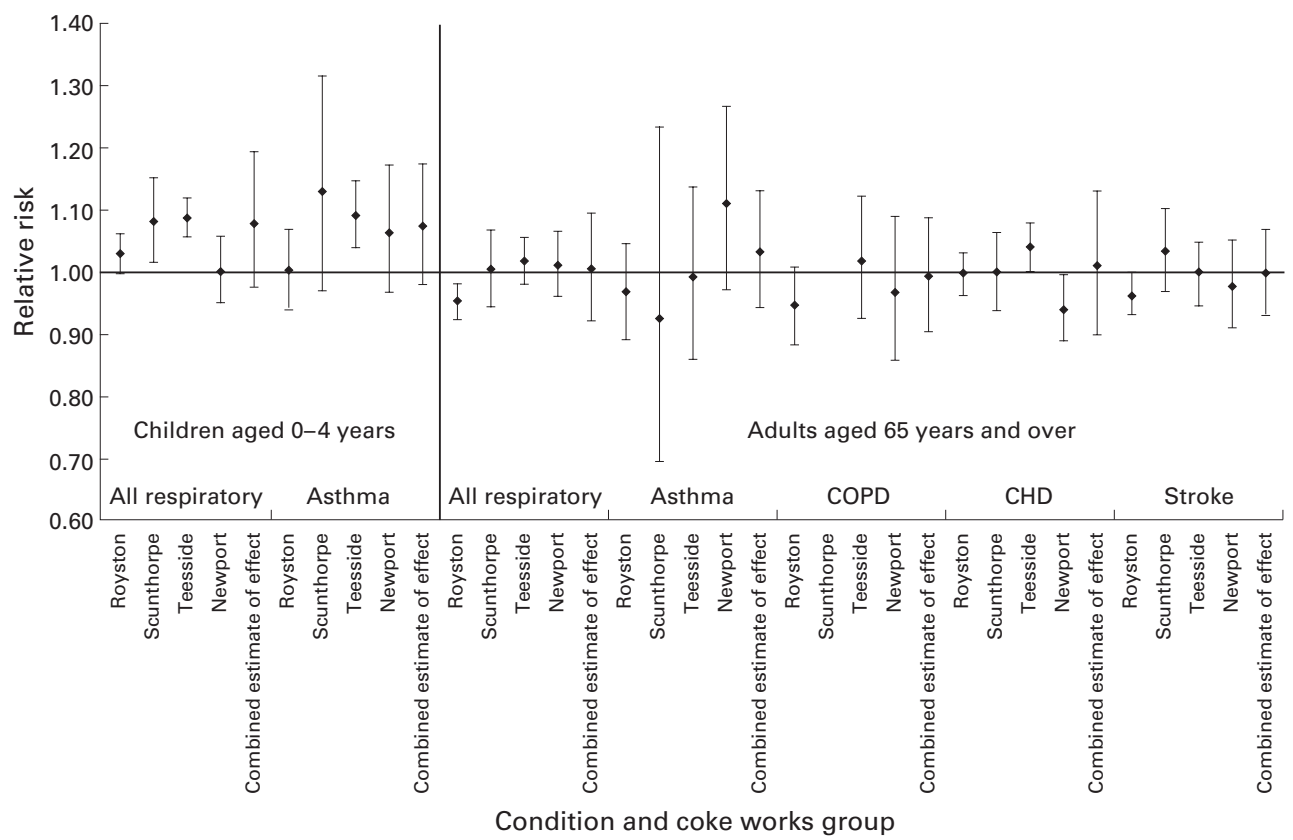

Figure 2 Relative risk per $1 \mathrm{~km}$ increase in proximity to nearest coke works for children under 5 and persons aged 65 years or over, adjusted for age, sex, deprivation quintile, and provider, including combined Bayesian hierarchical model estimates of effect. 


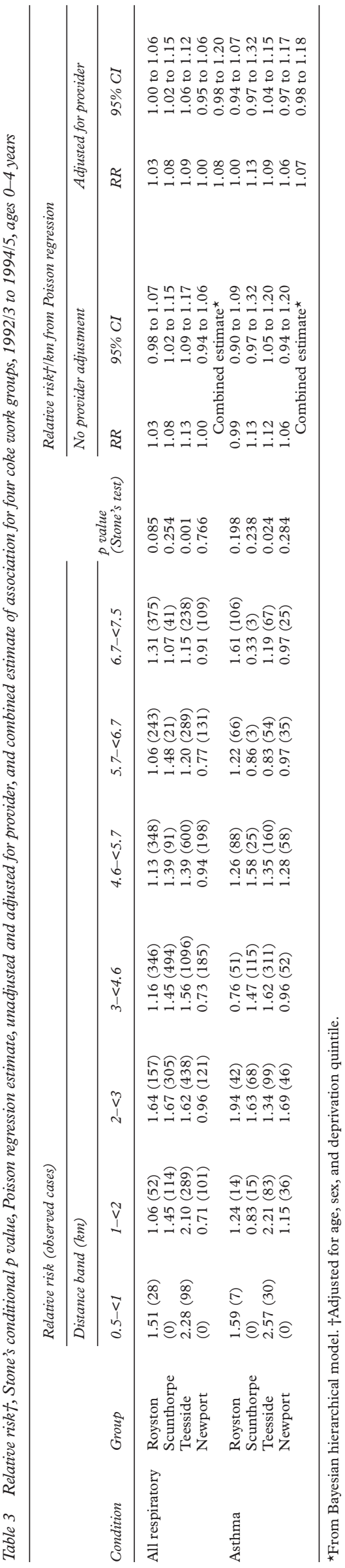

with an apparent gradation in risk from 2.28 (based on 98 cases) at $0.5-<1 \mathrm{~km}$ to 1.15 (238 cases) at $6.7-7.5 \mathrm{~km}$ for respiratory disease, and from 2.57 (30 cases) to 1.19 (67), respectively, for asthma. Relative risks (per km proximity) from the Poisson regression analysis were 1.13 (95\% CI 1.09 to 1.17$)$ and 1.09 (95\% CI 1.06 to 1.12 ) for respiratory disease without and with provider adjustment, respectively, and 1.12 (95\% CI 1.05 to 1.20$)$ and 1.09 (95\% CI 1.04 to 1.15), respectively, for asthma. Immediately surrounding the Teesside coke works the population is deprived, such that $83 \%$ of those living within $2 \mathrm{~km}$ are within the most deprived Carstairs quintile. When both deprivation and provider were removed from the regression model, the estimate for all respiratory admissions in children under 5 years became 1.16. None of the other Stone's tests was significant. Although estimated RR (per $\mathrm{km}$ ) for respiratory disease near Scunthorpe was 1.08 (95\% CI 1.02 to 1.15 ) both with and without provider adjustment, in contrast with Teesside, the RR within each of the seven distance bands did not show a clear gradient of declining risk with distance. Relative risks for all respiratory disease near Newport were below 1 for all distance bands.

\section{Discussion}

The main question under study was whether proximity to coke works emissions was associated with an increased risk of hospital admissions for cardiorespiratory disease. The point estimates (all non-significant) from the combined Bayesian random effects model (per km proximity to coke works) were between $1 \%$ lower risk (chronic obstructive pulmonary disease) and 3\% greater risk (asthma) at ages 65 or over, and $7-8 \%$ greater risk for respiratory disease and asthma in children under 5 years of age. These results, particularly for older people, offer little or no support overall to the thesis that proximity to an important source of particulate and sulphurous pollution had a measurable impact on health.

There was, however, evidence of significant heterogeneity between the regression estimates for individual coke work groups among children. In particular, a significant trend of higher risk with proximity to the Teesside site was apparent both for all respiratory disease and asthma in children under 5 years.

There has been longstanding concern over the perceived high levels of ill health in the Teesside area. ${ }^{29}$ A study of the health of residents near the industrial, petrochemical, and steel complex at Teesside, including the coke works, showed no clear evidence of any health effect except perhaps for lung cancer in women and a suggestion of a gradient in adults and children for self-reporting of more than 12 asthma attacks in the previous year. ${ }^{30} 31$ The petrochemical plant was also included in a national study of lymphohaematopoietic cancers near industrial complexes containing major oil refineries in Great Britain, but the results were largely negative. ${ }^{32} \mathrm{~A}$ study near the Monkton coke works in South Tyneside, North East England (which is now closed and 
therefore not included in the present study) also found significant excess reporting of respiratory and related problems among children living near the plant. ${ }^{16}$

Teesside is part of a much larger industrial complex which may itself be responsible for the strong trends observed in hospital admissions for respiratory illness among young children. There is also the possibility that we have incompletely adjusted for socioeconomic deprivation and provider effects. On the other hand, if the excess risk in deprived areas near the source reflects the increased exposure, then there is a danger of overadjustment (leading to conservative estimates of risk). In our view, further analysis of health statistics for children in the Teesside area, including better exposure estimates to account for pollution sources other than coke works, is indicated in order to help disentangle these possible effects.

A number of limitations need to be recognised. Firstly, while the health data were obtained from individual records located at the level of postcode (10-100 $\mathrm{m}$ resolution), the exposure data and data analysis were carried out at ecological (small area) level so that resulting risk estimates may not be directly applicable to individuals. ${ }^{33}$ Secondly, no allowance was made for migration, both into and out of the study area, and mobility through the study area as part of day to day activities. Data from linked census records in England and Wales (longitudinal study) have suggested that $67 \%$ of the population moved less than $2 \mathrm{~km}$ over a 10 year period, ${ }^{17}$ while residents near the Monkton coke works had been living at the same address for an average of 15 or more years. ${ }^{16}$ A recent paper examining health in Teesside suggested that migration is not a major issue. ${ }^{30}$ While migration could bias estimates of association in either direction, the most likely effect is toward the null (no association). Thirdly, the study used a simple radial dispersion-decline model to describe exposure to pollutants from the source, leading to possible misclassification of areas with respect to exposure and hence possible underestimation of any health effect. Previous studies, however, based on dispersion modelling ${ }^{16}$ and measurement around coke works, ${ }^{34}$ have indicated that the highest pollution concentrations are found within $2 \mathrm{~km}$ of coke works which gives some validation to this simple model. An attempt to construct a community profile of exposure to industrial air pollution using air quality reports, dispersion modelling, and questionnaire data in Teesside also suggested that proximity of residence was a reasonable surrogate for complex community exposure. ${ }^{35}$ Fourthly, when calculating indirectly standardised admission ratios, using the administrative region as a standard population, expected numbers of admissions in socioeconomically deprived residents close to the coke works may be underestimated (tending to overestimate the relative risk). This is because on some sites there may be greater deprivation within each quintile in the inner rings than in the standard population. However, in our regression analyses, which were based on rates within $7.5 \mathrm{~km}$, this is less of an issue.

The health data were derived from Hospital Episode Statistics and the Patient Episode Database for Wales which record all National Health Service hospital inpatient activity in England and Wales. Several factors that influence hospital admission are independent of disease prevalence and severity. General practitioner referral rates, ${ }^{36}$ supply of hospital beds, ${ }^{37}$ variations in admission policies and hospital access (which tends to be less for less privileged groups ${ }^{38}$ ), and distance from hospi$\mathrm{tal}^{39}$ are all important. The quality of hospital data is an important consideration..$^{41}$ Two groups (three coke works) were excluded from the analysis because of the poor quality of local hospital episode data which included failure to record a primary diagnosis or use of vague diagnoses, but we were unable to determine the accuracy of diagnostic coding for any group. Numbers and rates for Newport were also low compared with other coke work groups, suggesting the possibility of incomplete coverage. To the extent that such factors may vary between areas in the vicinity of coke works, an unknown degree of bias may have been introduced into the analyses. Some episodes are likely to be repeat admissions in the same subjects. The regression analysis for Teesside and Scunthorpe in children under 5 was repeated using individuals as the unit of analysis by linking admissions using date of birth, sex, and postcode. Although relative risks were slightly decreased, they remained significant.

In summary, we found no significant evidence overall for a health effect associated with living near to operational coke works in England and Wales. Trends of higher risk of respiratory hospital admission among children with proximity to the Teesside plant require further investigation. This should include improved definition of exposed areas through modelling of emissions both from the coke works and other major industrial sources in the area.

PA, PE, and LJ were involved in the conception and management of the project. $\mathrm{PA}$ and $\mathrm{AB}$ were involved in the development of the project with JW overseeing the statistics. PA and $A B$ prepared the first draft of this paper and LJ, JW and PE contributed to the final submitted version. PA is the guarantor.

Funding: The Small Area Health Statistics Unit is funded by a grant from the Department of Health, Department of the Environment, Transport and The Regions, Health and Safety Executive, Scottish Executive, National Assembly for Wales, and Executive, Scottish Executive, National Assembly for Wales, and
Northern Ireland Assembly. We thank the Office for National Statistics (formerly Office of Population, Censuses and Surveys), the Department of Health and Welsh Health
Information Services (NHS Wales), for provision of and permission to use vital registration and health event data.

This work is based on data provided with the support of the ESRC and JISC and uses census and boundary material which are copyright of the Crown, the Post Office and the ED-LINE Consortium. This research was supported, in part, by an equipment grant from the Wellcome Trust $(0455051 / \mathrm{Z} / 95 / \mathrm{Z})$. The views expressed in this publication are those of the authors and not necessarily of the funding departments.

1 Pope A, Bates D, Raizenne M. Health effects of particulate air pollution: time for reassessment? Environ Health Perspect 1995;103:472-80.

2 Committee of the Environmental and Occupational Health Assembly of the American Thoracic Society. Health effects of outdoor air pollution. Am 7 Respir Crit Care Med of outdoor air

3 Dockery D, Pope A. Epidemiology of acute health effects: summary of time-series studies. In: Wilson, R, Spengler J, 
eds. Particles in our air, concentrations and health effects. Harvard University Press, 1996:123-47.

4 Schwartz J, Dockery D. Increased mortality in Philadelphia associated with daily air pollution concentrations. Am Rev Respir Dis 1992;145:600-4.

5 Schwartz J. Particulate air pollution and daily mortality in Detroit. Environ Res 1991;56:204-13

6 Katsouyanni K, Touloumi G, Spix C, et al. Short term effects of ambient sulphur dioxide and particulate matter on mortality in 12 European cities: results from time series data from APHEA project. BMF 1997;314:1658-63.

7 Steadman JR, Anderson HR, Atkinson RW, et al. Emergency hospital admissions for respiratory disorders attributable to summer time ozon

8 Dockery D, Pope A III, Xu X, et al. An association between air pollution and mortality in six US cities. $N$ Engl f Med 1993;329:1753-9.

9 Pope A III, Thun M, Namboodiri M, et al. Particulate air pollution as a predictor of mortality in a prospective study pollution as a predictor of mortality in a prospective study

10 Pope A, Dockery D. Epidemiology of chronic health effects: cross-sectional studies. In: Wilson, R, Spengler J, eds. Particles in our air, concentrations and health effects. Harvard University Press, 1996:149-68.

11 Moffatt S, Phillimore P, Bhopal R, et al. 'If this is what it's doing to our washing, what is it doing to our lungs?' Industrial pollution and public understanding in north-east England. Soc Sci Med 1995;41:883-91.

12 Elliott P, Shaddick G, Kleinschmidt I, et al. Cancer incidence near municipal solid waste incinerators in Great Britain. Br 7 Cancer 1996;73:702-10

13 Michelozzi P, Fusco D, Forastiere F, et al. Small area study of mortality among people living near multiple sources of air pollution. Occup Environ Med 1998;55:611-5.

14 Lave L, Leonard B. Regulating coke oven emissions. In: Paustenbach D, ed. The risk assessment of environmental and human health hazards. New York: John Wiley, 1989.

15 Her Majesty's Inspectorate of Pollution. Chief Inspector's Guidance Note Fuel Production Processes, Combustion Processes Guidance Note Fuel Production Processes, Combustion Processes (including Power Generation) S2 1.06

16 Bhopal RS, Phillimore P, Moffat S, et al. Is living near a coking works harmful to health? f Epidemiol Community Health 1994;48:237-47.

17 Dolk H, Thakrar B, Walls P, et al. Mortality among residents near coke works in Great Britain. Occup Environ Med 1999, 56:34-40

18 Dolk H, Pattenden S, Vrijheid M, et al. Perinatal and infant mortality and low birth weight among residents near cokeworks in Great Britain. Arch Environ Health 2000;55:2630.

19 Payne JN, Coy J, Patterson S, et al. Is use of hospital services a proxy for morbidity? A small area comparison of the prevalence of arthritis, depression, dyspepsia, obesity, and prevalence of arthritis, depression, dyspepsia, obesity, and disorders in England. 7 Epidemiol Community Health 1994; 48:74-8.

20 Walters S, Phupinyokul M, Ayres J. Hospital admission rates for asthma and respiratory disease in the West Midlands: their relatic

21 Carstairs V, Morris R. Deprivation and health in Scotland. Aberdeen: Aberdeen University Press, 1991.

22 Simpson S, Tye R, Diamond I. What was the real population of local areas in mid-1991? Working Paper 10, Estimating
With Confidence project. Department of Social Statistics, University of Southampton, Southampton, 1995.

23 Welsh Common Services Agency. Data coverage and completeness for 1992/92, 1993/94, 1994/5

24 Elliott P. Point sources of air pollution: investigation of possible health effects using small area methods. In: Ayres J, Richards RJ, Maynard RL, eds. Air pollution and health. Volume II, Air Pollution Reviews. London: Imperial College Press, 2000 (in press).

25 Shaddick G, Elliott P. Use of Stone's method in studies of disease risk around point sources of environmental pollution. Stat Med 1996;15:1927-34.

26 Diggle P, Morris S, Elliott P, et al. Regression modelling of disease risk in relation to point sources. $\mathcal{F} R \operatorname{Stat} \operatorname{Soc}(A)$ 1997; 160:491-505.

27 Spiegelhalter D, Thomas A, Best N. WinBUGS user manual. Version 1.1.1, Cambridge, UK, 1998 (http://www.mrcbsu.cam.ac.uk/bugs)

28 Whitehead A, Whitehead J. A general parametric approach to the meta-analysis of randomised controlled trials. Stat Med 1991;10:1665-79.

29 Phillimore P, Morris D. Discrepant legacies: premature mortality in two industrial towns. Soc Sci Med 1991;33: 139-52

30 Bhopal RS, Moffat S, Pless-Mulloli T, et al. Does living near a constellation of petrochemical, steel, and other industries impair health? Occup Environ Med 1998;55:812-22.

31 Pless-Mulloli T, Phillimore P, Moffat S, et al. Lung cancer, proximity to industry and poverty in Northeast England. Environ Health Perspect 1998;106:189-96.

32 Wilkinson P, Thakrar B, Walls P, et al. Lymphohaematopoietic cancers around all industrial complexes that include major oil refineries in Great Britain. Occup Environ Med 1999;56:577-80

33 Diggle PJ, Elliott P. Disease risk near point sources: statistical issues for analyses using individual or spatially aggregated data. F Epidemiol Community Health 1995; 49(Suppl 2):S20-7.

34 Thomas B. Pollution at coke works. Joint report of investigations into the measurement of polycyclic aromatic hydrocarbons and benzene, toluene and xylene in and around coke works. Commission of the European Communities. EUR 13196 EN 1991

35 Pless-Mulloli T, Dunn CE, Bhopal R, et al. Is it feasible to construct a community profile of exposure to industrial air construct a community profile of exposure to

36 Cummins RO, Jarman B, White PM. Do general practitioners have different "referral thresholds"? BMF 1981;282: $1037-40$

37 Royston GHD, Hurst JW, Lister EG, et al. Modelling the use of health services by populations of small areas to inform the allocation of central resources to larger regions. Socio-econ Plann Sci 1992;26:169-80.

38 Majeed A, Chaturvedi N, Reading R, et al. Monitoring and promoting equity in primary and secondary care. $B M F$ 1994;308:1426-9.

39 Jones AP, Bentham G. Health service accessibility and deaths from asthma in 401 local authority districts in England and Wales, 1988-92. Thorax 1997;52:218-22.

40 Williams DRR, Anthony P, Young RJ, et al. Interpreting hospital admissions data across the Körner divide: the example of diabetes in the North Western region. Diabetic Med 1994;11:166-9.

41 McKee M. Routine data: a resource for clinical audit? Quality Health Care 1993;2:104-11. 